\title{
Retrofitting suburbia: Is the compact city feasible?
}

3 L. Rice RIBA

This paper examines the role of retrofitting existing suburbs to deliver more sustainable lifestyles. The policy of intensification of existing urban and suburban areas, referred to as a 'compact city' strategy, has been promoted by the UK government and is linked to claims that higher density mixed-use areas promote more sustainable lifestyles. Whilst the policy is normally considered at the 'strategic' level, it is at the local level that its effects are felt and realised. This research aimed to answer two questions: Is it physically feasible to retrofit existing suburban areas? If so, do they deliver the claimed sustainability benefits? The research considered published recommendations for restructuring existing urban form. The project found that retrofitting the suburbs is feasible and viable at local level and, in some situations, can enable more sustainable lifestyles, in particular improved accessibility, social inclusion, and physical and mental health benefits.

\section{INTRODUCTION}

This paper examines the retrofitting of existing UK suburbs as part of the UK government's policy towards more sustainable development. Underpinning the approach to sustainable development in relation to urban form is the 'compact city' strategy. Two key questions were explored during this research:

(a) Is it physically feasible to retrofit existing suburban areas? (b) If so, do they deliver the claimed sustainability benefits?

This work adopts current UK government policies and directives on sustainable urban form as the basis upon which to examine these questions. Underpinning much current policy are the principles set out in the government-backed Urban Task Force report (UTF, 1999), which has been very influential in the creation of subsequent policy (Williams, 1999). UTF compact city principles were applied to two suburban case study areas in Greater London over the period 2001-2031.

The paper is structured as follows. The links between compact urban form and sustainability are set out to provide the rationale for the study in Section 2. Compact city theory, as set out in the UTF report, is explored in Section 3. This section examines the physical structure of the compact city to provide criteria to answer the first research question and defines the sustainability indicators used to answer the second research question. Section
3 concludes by briefly examining the UK compact city strategy in practice.

The paper then sets out the methods of research used (Section 4). In order to answer the questions, it was necessary to understand the economic, social and environmental context for the case study areas. The multi-methodological approach used to do this is explained and the retrofitting strategy is set out. The paper then presents the empirical data related to density, accessibility and urban form as the criteria for assessing the feasibility of retrofitting. The paper concludes with a discussion on the sustainability benefits of retrofitting suburbia.

\section{WHAT IS A COMPACT CITY?}

The compact city refers broadly to an urban form with the characteristics of high-density mixed-use urban development, with walkable neighbourhoods and good public transport provision. It is the traditional form of many UK historic towns and cities (UTF, 1999). Most of the UK, however, is suburban rather than urban in character and is characterised by lowdensity single-use land zoning, with car-dependent transport (EEA, 2006). The compact city strategy promotes a set of policies and approaches to urban planning and governance that would shift from low-density urban 'sprawl' towards new higher density, mixed-use urban forms (CEC 1990; Williams, 1999).

\section{I. Why is it relevant?}

Compact city strategy is of relevance because of its relationship to sustainability. The strategy forms part of the wider metadiscourse on sustainable futures, particularly the impact of climate change (Jenks et al., 1996). Urban areas are major contributors to unsustainable lifestyles and the built environment is increasingly part of the wider attempt to promote a more sustainable future. Urban form affects many aspects of behaviour that contribute to more or less sustainable lifestyles and there are a wide range of other economic, environmental and social sustainability indicators that are related to the built environment (Defra, 2009). There is general agreement that urban form can improve sustainability, but there is disagreement about the optimal way to modify urban form to gain sustainability benefits (Breheny, 1992; Haughton and Hunter, 1994; Williams et al., 2000).

\subsection{What is sustainable development?}

Sustainable development is difficult to define and is a much contested area. For this paper, the definition used is the UK 
government's approach, which is based on the Brundtland report: 'development which meets the needs of the present without compromising the ability of future generations to meet their own needs' (Brundtland, 1987). This forms the central thesis of the UK government sustainable development strategy. Progress towards sustainability in the UK is measured by a series of indicators that cover a wide array of different factors (Defra, 2009; DETR, 1999). Only some of these relate specifically to urban form and it those factors that have been taken into consideration for this research. Physical structure is deemed critical to sustainable development. Evaluation of sustainability requires holistic balancing of social, economic and environmental factors. The aim of the compact city is to encourage and support changes to behaviour and lifestyle (Barton et al., 1995), but many of the claims of sustainability benefits attributed to the compact city have been questioned (Breheny, 1992; Breheny and Rookwood, 1993; Frey, 1999). It is clear there is no simple 'cause and effect' between sustainability and a compact city. Instead, there is a complex interrelationship of urban form and human behaviour that must be coordinated to deliver the

4 benefits of a compact city strategy (Williams and Dair, 2007).

\subsection{How does the compact city strategy relate to wider policy?}

The compact city strategy has been implemented by central and local governments in Europe, America and the UK in response to calls for a more sustainable future. Much of the theory has developed from the 'new urbanist' movement and the UK has broadly adopted these principles over the last ten years. In the USA, the compact city takes the form of smart growth strategies and transit-orientated development (Dittmar and Ohland, 2003). In Europe, there is broadly the same approach as taken in the UK sustainable communities programme (ODPM, 2003), which has a major focus on the regeneration of existing areas. In each of these countries/regions the compact city has been adopted as the best available option for implementing sustainable development as a traditional compact city or some form of poly-centric city (Frey, 1999)

\subsection{What is retrofitting?}

Retrofitting of suburbia is described by Dunham-Jones and Williamson (2009: p. xii) as going beyond simply installing new elements to an existing context towards 'the idea of systemic, long-lasting transformative change.' Retrofitting is thus involved with intensification as well as restructuring and transforming the suburban townscape. This research examined a number of approaches to retrofitting to contextualise the design methods. These included strategies that deal with suburban intensification (Falk, 2006; Urbed, 1999a) and with making new, more compact suburbs (Kochan, 2007; TCPA, 2007). This can be achieved through a variety of intensification strategies. For example, large residential properties can be converted into smaller apartments or demolished to build apartments at higher densities; another approach is the splitting of large gardens into sites for new smaller dwellings. d'Avoine and Melhuish (2007) proposed the development of small gardens to accommodate new dwellings. Their research project studied the insertion of new dwellings between existing properties, including the space between semi-detached properties, and any brownfield sites within the study areas were also used for development where appropriate. Urbed (1999a) examined the regeneration of small brownfield sites within a suburban context and council-owned housing estates have also been considered (Wandsworth Council, 2004). The identification of sites there followed the housing capacity approach proposed in the Urbed (1999b) report, which describes 11 potential sites: 'subdivision of existing housing, flats over shops, empty homes, previouslydeveloped vacant and derelict land and buildings (non housing), intensification of existing areas, redevelopment of existing housing, redevelopment of car parks, conversion of commercial buildings, review of existing housing allocations in plans, review of other existing allocations in plans and vacant land not previously developed.'

\subsection{Why retrofit the suburbs?}

There has been relatively little research into the intensification of suburbs, with the concept often dismissed as unfeasible before any detailed examination of the proposal (Gwilliam et al., 1998; Scheer and Petkov, 1998; Williams, 1999). This is despite growing use of the principles of the compact city for new 'sustainable' suburban development (Prince's Foundation, 2000; TCPA, 1997). The UTF (1999: p. 51) called for much more widespread intensification and restructuring of cities, stating 'for some suburban areas this could involve 'retrofitting' or 'recycling' land and buildings'. The existing suburbs house over $80 \%$ of the UK population (Echenique and Homewood, 2003). According to compact city theory, the greatest impact on sustainability would be through retrofitting the existing suburbs.

\section{THE URBAN TASK FORCE 1999 REPORT}

The UTF (1999) report Towards a New Renaissance was an influential government-backed document that informed UK policy towards encouraging more compact cities (Williams, 1999). The report led, in part, to the publication of a white paper (DETR, 2000) and now forms the basis of much current planning and development policy centred around the principle of 'sustainable development'. The central tenet in planning policy statement 1: delivering sustainable development (DCLG, 2006) aims for the 'delivery of sustainable development through the planning system.' This ambition is reflected across a wide range of directives, of which urban planning is one element, aimed at delivering development which enable and support sustainable lifestyles.

The 1999 UTF report set out relatively clear guidelines on how urban form should be restructured to deliver benefits to sustainability. Much of this guidance was aimed at the strategic city-wide level (Figure 1) with some detail of how this might transfer at the local level. This research project adopted the principles set out by the UTF as the basis upon which to restructure and retrofit an existing area. Although much of the literature refers to the 'urban' condition, the guidance is equally valid for suburban areas. The UTF report (1999: p. 11) set 'excellence in urban design' as the cornerstone of the urban renaissance. The main characteristics for the physical urban form were: higher density cities; integrated urban transport systems (i.e. promoting public transport, walking and cycling); good accessibility; mixed-uses; and increasing the supply of brownfield development (Barton et al, 1995; Dair and Williams, 1999). 

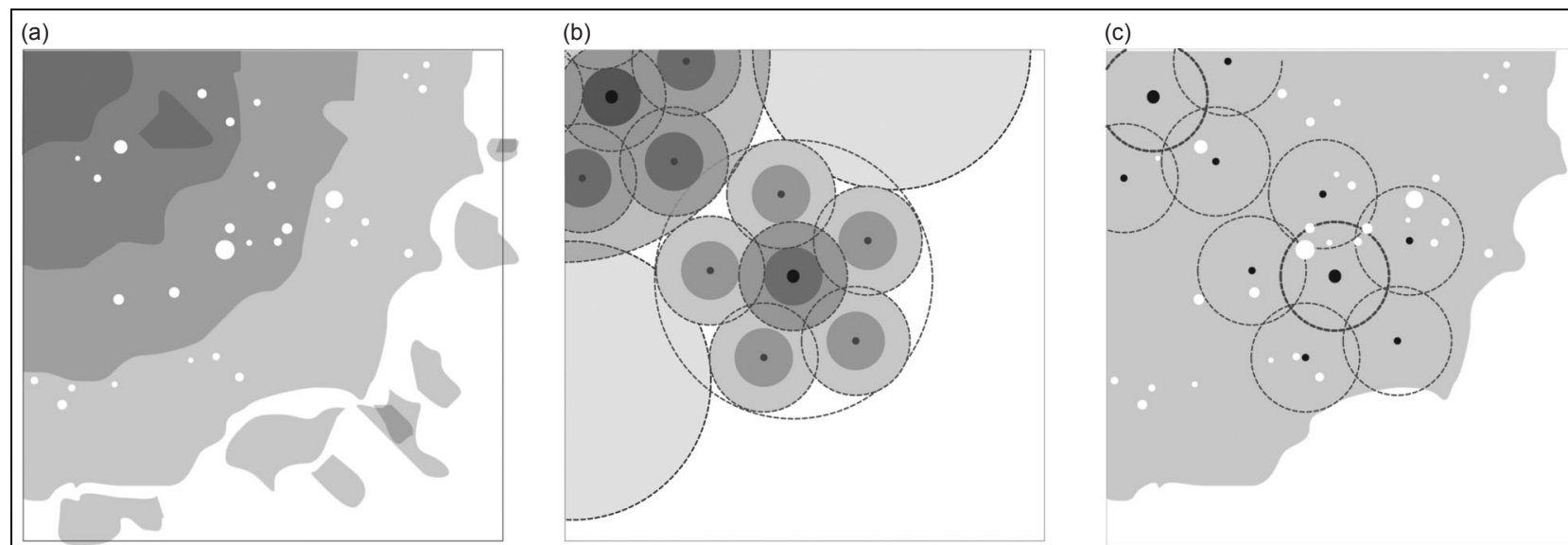

Figure I. Illustration of the compact city process. (a) Traditional 'sprawling' suburbs with density decreasing away from the centre and scattered local centres. (b) The idealised compact city form, with distinct neighbourhood units forming a crystalline shape around a larger 'district' centre. (c) An overlay of the two reveals the mismatch between existing local centres and the locations of optimal local centres (copyright: Rogers Stirk Harbour + Partners/Louis Rice. ${ }^{\odot}$ Crown Copyright/database right 2007. An Ordnance Survey/ EDINA supplied service. 200I Census, Output Area Boundaries. ( ) Crown Copyright 2007. National statistics website: www. statistics.gov.uk. () Crown Copyright 2007. Crown copyright material is reproduced with the permission of the Controller of HMSO. The Naptan Database is Crown Copyright)

from the centre and scattered local centres. Figure 1(b) shows the idealised compact city form, with distinct neighbourhood units forming a crystalline shape around a larger 'district' centre. Figure 1(c), which overlays the two, reveals the mismatch between existing local centres and the location of optimal local centres.

\section{I. The compact city and sustainability}

3.1.1. Density. Density is critical to "creating compact urban developments' (UTF, 1999: p. 11). Compact urban forms are characterised and created primarily by high density. Housing density in Greater London is between 15 and 40 dwellings per hectare (dph) (Kochan, 2007: p. 23). Higher densities are required to promote 'walkable' neighbourhoods that are conducive to walking and cycling and a sustainable transport system, as part of a wider sustainable development strategy. The minimum level of density proposed is approximately 50 dph (MJP, 2005; Urbed/GLA, 2002; UTF, 2006). Although there is no upper limit to density set in the UTF (1999) report, density levels between 50 and $80 \mathrm{dph}$ remain suburban (rather than urban) in character (Barton et al., 2003). Density levels should be related to local centres and public transport, with density reducing with distance. Within the local centres, there should be a mixture of shops, services and residential use.

3.1.2. Accessibility. Accessibility is critical for enabling sustainable development. The tendency for people to walk is closely related to distance and, at high density, greater numbers of people can walk or cycle to nearby facilities (Lenthe et al., 2005). The UTF (1999) report lists a number of different key destinations (schools, bus stops, train stations, etc.) and their pedshed (i.e. the distance people will walk to a destination). Accessibility is also related to a number of sustainability indicators. Highly accessible mixed-use neighbourhoods can provide opportunities for social capital (CEC, 1990; Leyden, 2003) and a sense of community (RCEP, 2007). In turn, social capital can reduce depression and help improve physical health (Kawachi et al., 1996). People with lower levels of social capital are more likely to be obese, have more mental health problems and lower wellbeing (Wilkinson and Marmot, 2003).

3.1.3. Transport. The qualities of the compact urban form (density, accessibility and mixed use) are aimed at "creating compact urban developments, based upon... integrated urban transport systems, that prioritise the needs of pedestrians, cyclists and public transport passengers' (UTF, 1999: p. 11). The relationship between compact cities and a shift away from carbased transport is heavily contested: many argue for this connection (Ecotec, 1993; Sherlock, 1996), but there are equally strong counter arguments (Stretton, 1996; Breheny, 1995). The Greater London Authority (GLA, 2004) has developed a grid matrix connecting areas of accessibility to public transport. These public transport accessibility levels (PTALs) relate accessibility to public transport to the density of future development as part of the GLA's sustainable development strategy.

\subsection{The physical structure of a compact city}

Accepting the current UK approach to sustainable development, the paper now examines the UTF guidance on urban structure in greater detail. The UTF (1999) report sets clear criteria on the physical size and shape of the compact city. It is a settlement of small 'neighbourhood' units carefully related to each other to generate a larger 'district' (Figure 1). Each neighbourhood is defined by distance based on accessibility to a local centre and by critical population levels required to sustain those centres and other services (UTF, 1999: p. 55). The report (UTF, 1999: p. 60) states that 'the acceptable 500-metre or five-minute walking limit' is the optimal size of a neighbourhood radius to the edge of the shopping centre A 'centre' is not a fixed size and the walkable distance is measured to the edge of the shops rather than the centre, which is an approximately $800 \mathrm{~m}$ radius for each neighbourhood. These are shown in Figure 2. The report also specifies the populations required within each neighbourhood for certain facilities, for example, a local centre (20003000 people) and a neighbourhood (5000-10 000).

The relationship of each of these individual neighbourhoods to the 'district' can be mapped out, as also shown in Figure 2 . 


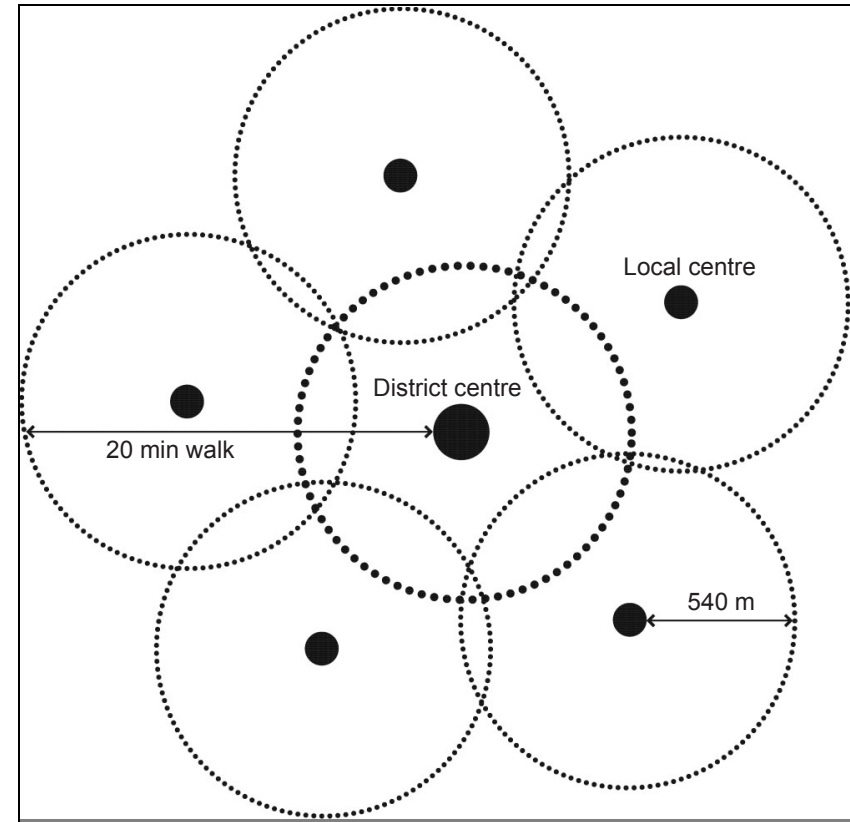

Figure 2. Diagram of the compact city: five local neighbourhoods surrounding a district centre (copyright: Rogers Stirk Harbour + Partners/Louis Rice)

The district centre requires a population of 25 000-50 000 (Barton et al., 2003; UTF, 1999: p. 55). This centre has a wider range of services, shops, facilities and greater public transport accessibility. The UTF report proposes a $20 \mathrm{~min}$ walk to the district centre. Most of the population in the hinterland of the district centre would be within this walkable distance.

In conclusion, there are four criteria upon which to assess the feasibility of retrofitting suburbia: (a) if 'sustainable' density levels be reached

(b) accessibility to schools, public transport and local centres

(c) if local neighbourhood units can be created

(d) if the large district area can be achieved.

\subsection{UK compact city experience}

Over the last decade, compact city principles have formed the basis of UK 'sustainable development'. There has been growth of one- and two-bedroom apartments in urban locations. There has been redevelopment of brownfield sites (Williams, 1999.) During this 'urban renaissance' the existing suburbs have remained relatively unaffected physically, although they have been slowly depopulating (ONS, 2001). Reducing household sizes, an ageing population living for longer (often as lone residents), increased levels of divorce and separation, and new lifestyle choices (people wishing to live alone) have meant that the average number of people per household has dropped significantly (Williams, 2009). Reductions in local populations can affect the viability of local shops and services, school catchments and public transport. There has, at the same time, been an increasing car dependency, reduced levels of walking and cycling, increasing levels of obesity and increases in mental health problems, some of which have been related to urban form (CABE, 2006; Larkin, 2003; Lavin et al., 2006).

\section{RESEARCH METHOD}

\section{I. The study areas}

The project examined two case study sites in Greater London, Harrow and Barking, both of which are suburban in character with some local centres and a larger district centre (Figure 3). The research examined each site, from 2001 to predictions for 2031. The sites were chosen to have a population of

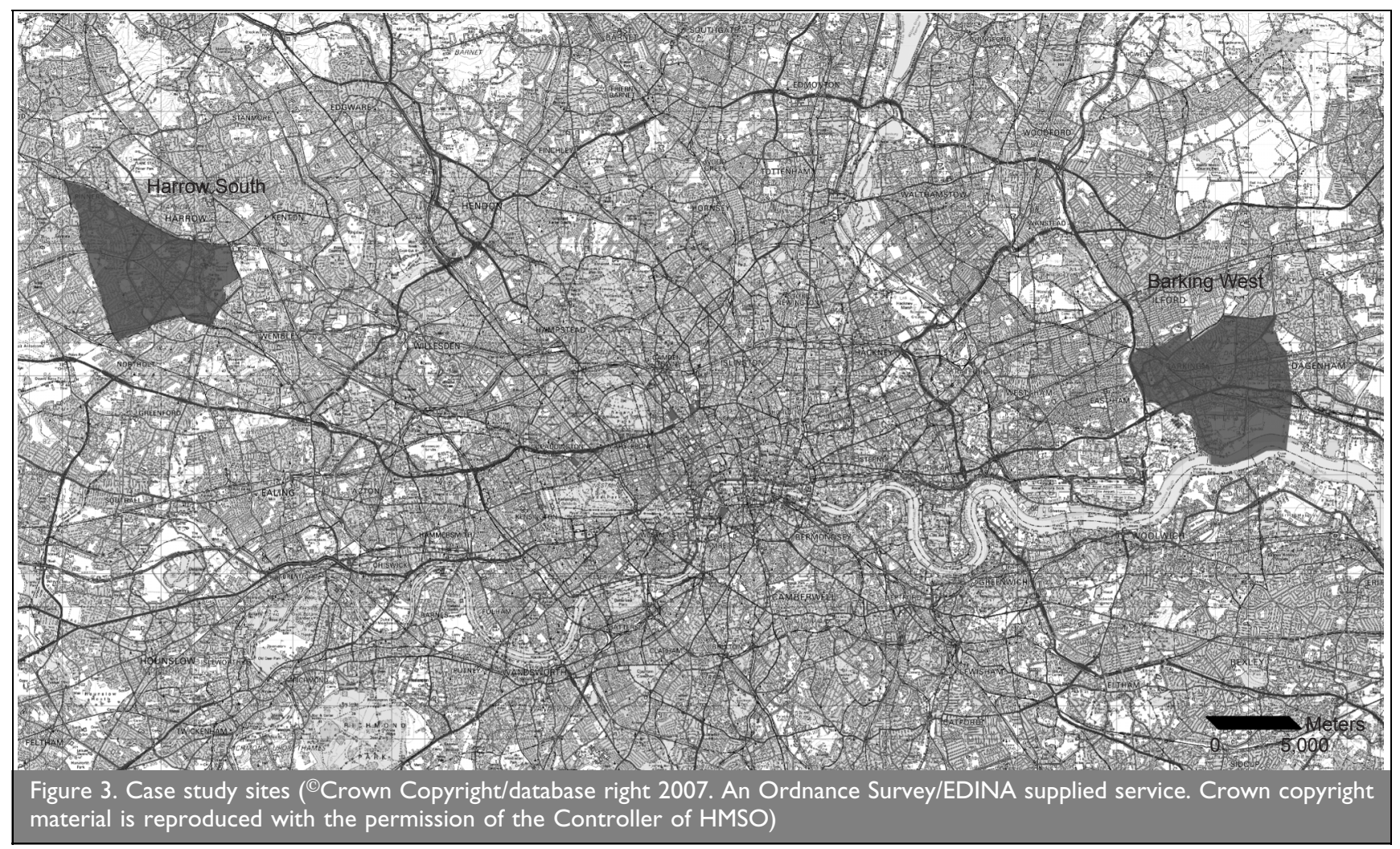


approximately 65000 in order to allow the examination of a full UTF 'district' sized settlement.

\subsection{Forecast data: 2031}

For each study area, a partnership was created with the local authority; this enabled sharing of data, statistics and local knowledge. The sites were also chosen to correspond with land use transport model (LUTM) boundaries so that these data could be used in the study areas (Echenique et al., 2009). (The work on the LUTM was carried out in partnership with Cambridge University.) These LUTM housing forecasts across the region, based on housing capacity studies, were generalised for larger areas of the city although they did align with the boundaries of the case study areas. The research attempted to connect these city-wide strategic forecasts down to the smallest local level urban form (i.e. to individual plots). Existing local authority housing capacity studies were also used.

\subsection{Research through design}

The research used urban design methods advocated by UK government, following guidance set out in the Urban Design Compendium (English Partnerships, 2000) and By Design (DETR/ CABE, 2000). This initially required the use of urban design methods including a 'research through design' process (Frayling, 1993; Rendell 2004) to provide a link between strategic predictions and how they translated on the ground. Urban design methods involved site analysis and site appraisal to develop an understanding of the local area and its context. This included an investigation, with local partners, of environmental, social and economic conditions. For each case study area, the 2031 housing forecasts were retrofitted into the existing context. The design scheme physically located each new allocation of housing within the existing context, as well as restructuring movement networks, local centres, mixing of functions and land uses. The nature of the streetscape was also addressed with greater use of home-zones and alternative street designs, following the advice set out in the Manual for Streets (DfT, 2007).

\subsection{Working process}

For each study area a '2001 baseline' condition was produced. The existing suburban layouts were input into a geographic information system (GIS) (see Figure 4) containing a series of information sets: road networks, footpaths, population data, UK borders data, public transport routes and timetables, trainstations and bus-stop locations. Local authority local plan data were used for land uses (retail locations, primary and secondary schools, and greenspaces/parks). These metrics recorded the current levels of accessibility and density. The metrics for 2031 record the accessibility performance of the suburbs that were modified through retrofitting with housing based on capacity studies. Metrics were produced to record the changes to accessibility through physical restructuring.

Different meetings were held according to the phase of research. The first meeting used the local knowledge of stakeholders from planning control and development, transport planners, business leaders, environmental organisations, building control and local heritage groups to inform the 2031 scenario. The first stakeholder meeting led to further development of the urban design process and repetition of the GIS analysis. This was then presented at the second stakeholder meeting. The stakeholders used the Spectrum sustainability appraisal technique of evaluating proposals (Barton and Grant, 2008). Spectrum enables stakeholders to appraise different aspects of a proposal, with recommendations on further action or changes required, using a traffic-light rating system. Spectrum also uses a holistic overview of the development scheme, balancing economic,

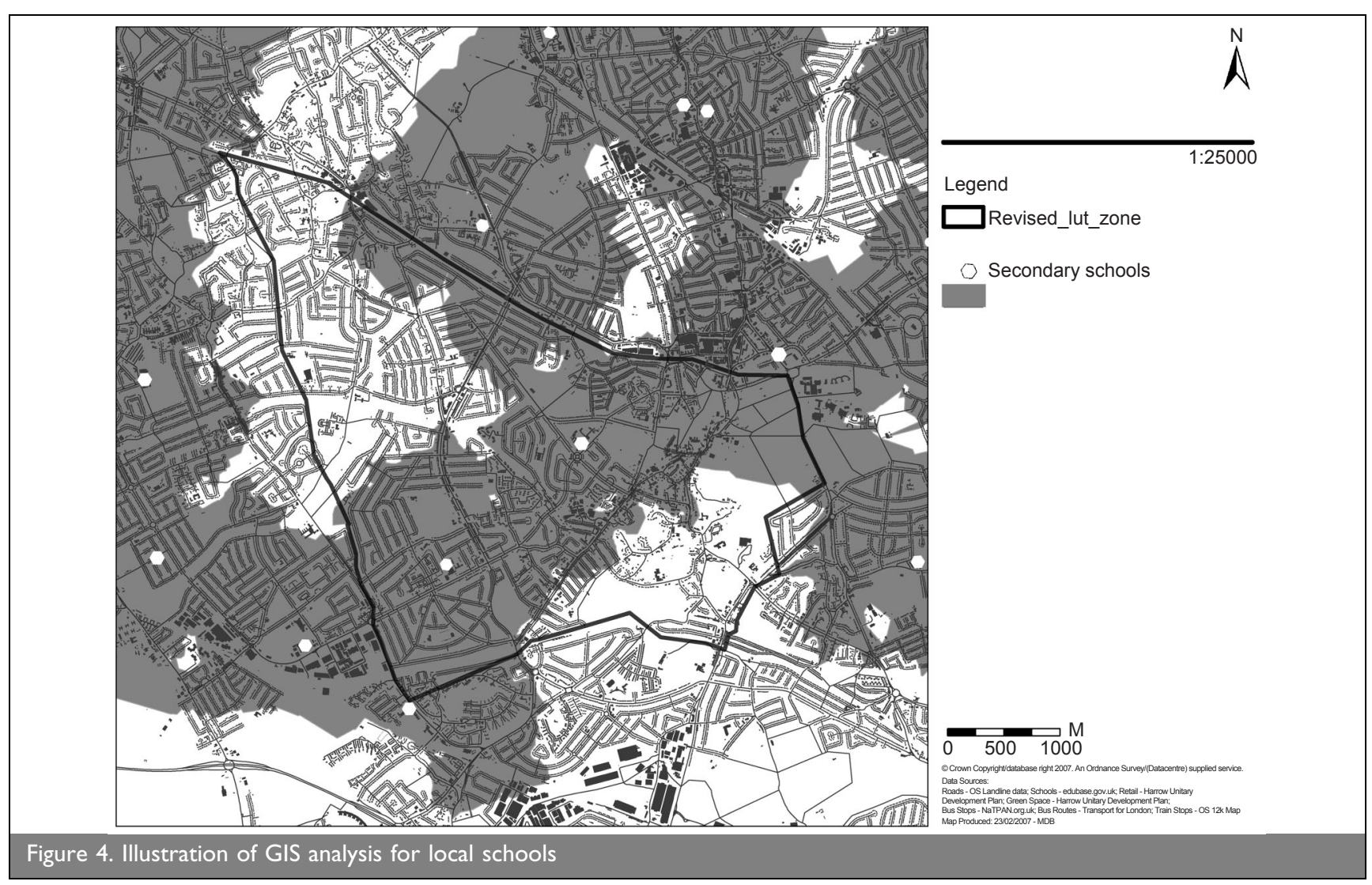




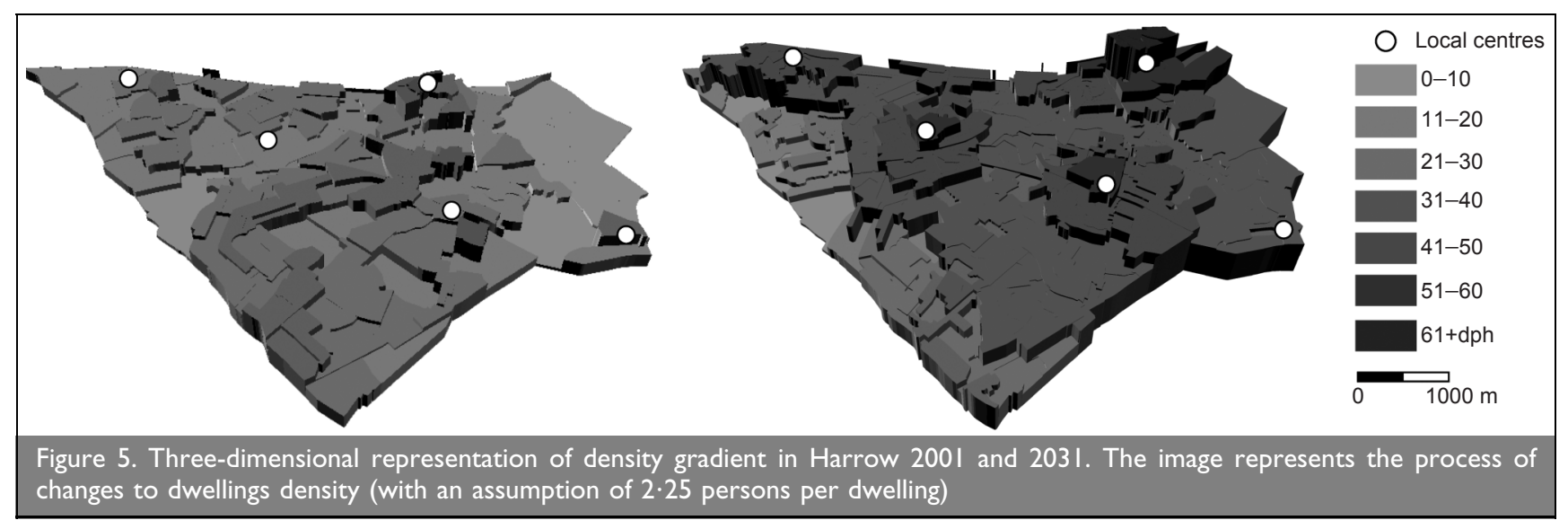

social and environmental aspects. The stakeholder meetings provided additional contextual information for the case study scenarios.

\section{RESULTS}

This section begins by presenting the findings in relation to the first research question: Is it feasible to retrofit existing suburban areas? Both study areas are presented together as the results are very similar. The results then examine the second research question: Do they deliver the claimed sustainability benefits?

According to the UTF, 'sustainable' densities are 45 dph or more, and these densities should correspond to PTALs. Density should not be increased across the entire area, but formed into graded peaks of density related to PTAL. Figure 5 shows the effect on density of retrofitting suburbia in Harrow from 2001 to 2031. The 3D representation shows how there is a change from the relatively 'flat' level of suburban density - generally around 25$30 \mathrm{dph}$. By 2031, density is highest (over $50 \mathrm{dph}$ ) in the most accessible areas with a gradual lowering of density with distance from the centres. Due to the existing layout of the suburban form, it was difficult to achieve densities much higher than $65 \mathrm{dph}$. To achieve densities above this level required comprehensive restructuring, which is beyond the scope of retrofitting.

Areas beyond this were not retrofitted as PTALs were too low to justify further intensification. Barking showed a similar pattern with regards to density. 'Single-family' housing (i.e. a house with a garden) was the dominant form of housing type under the

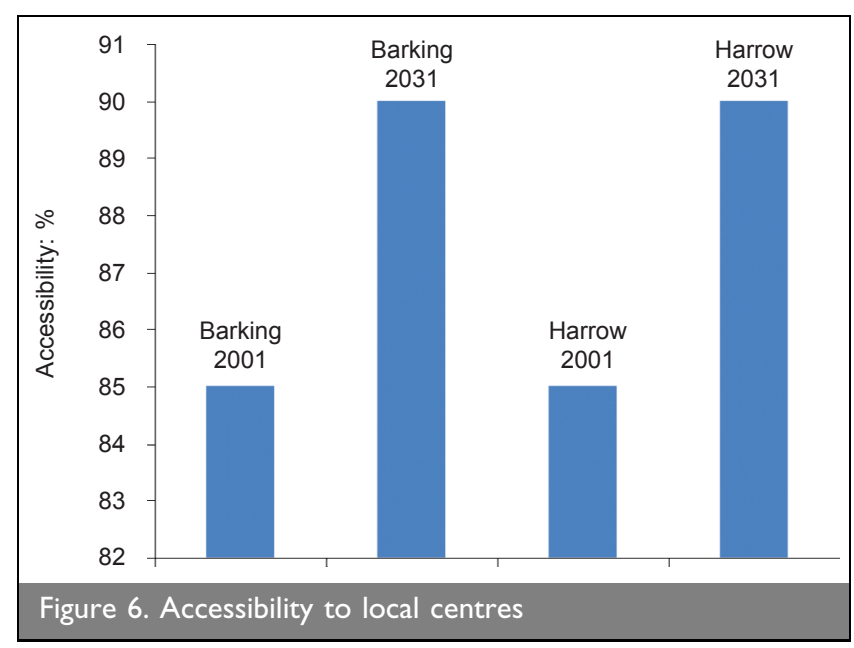

retrofitting approach. At present, with current compact city policies, there is a shortfall of such housing, resulting in higher density apartment-block development. Retrofitting these study areas was more able to provide the capacity to match 'family' housing demand.

\section{I. Does accessibility improve?}

The percentage of residents in the study area within $800 \mathrm{~m}$ of local centres was recorded in 2001 and for 2031 (Figure 6). In both Harrow and Barking there was a 5\% increase in accessibility. These figures represent accessibility across the entire study area. The levels of accessibility for the population exclusively in dwellings retrofitted since 2001 were even higher.

Figure 7 records accessibility to primary schools and secondary schools separately. The study areas were suburban in character and had slightly higher levels of households with children than the national average. Secondary schools have $1500 \mathrm{~m}$ pedsheds, while primary schools have $600 \mathrm{~m}$ pedsheds, reflecting the shorter distance younger children walk (Barton et al., 1995). Accessibility to primary schools in both study areas was very similar, with levels over 60\%. There was a slight increase in primary school accessibility by $2 \%$. Existing accessibility to secondary schools is good, with levels over 70\%. Secondary schools showed an $8 \%$ increase by 2031 to almost $80 \%$, which would be a relatively high level of accessibility.

Accessibility to bus services was based on distance to individual bus stops rather than bus routes (Figure 8). Frequency of services was also rated, with at least six buses per hour considered good or excellent. Accessibility to bus services in

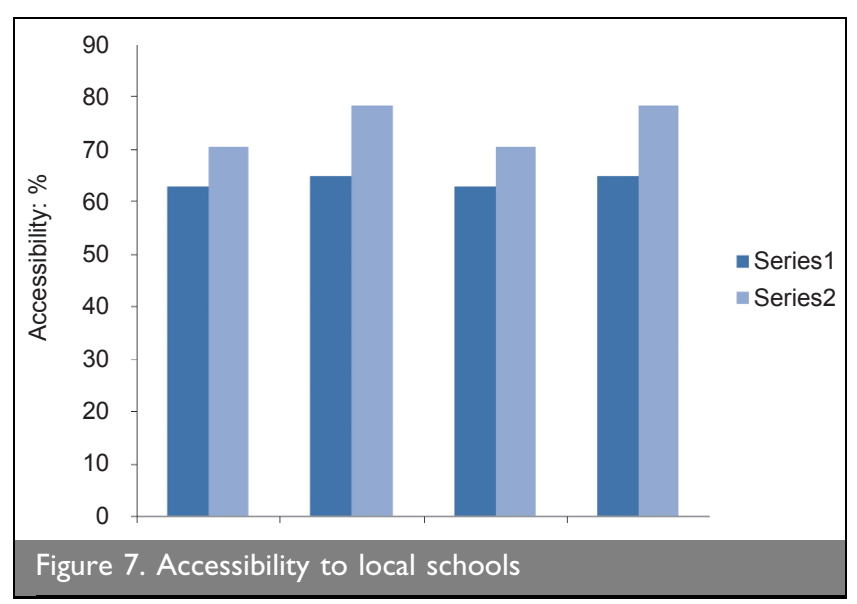




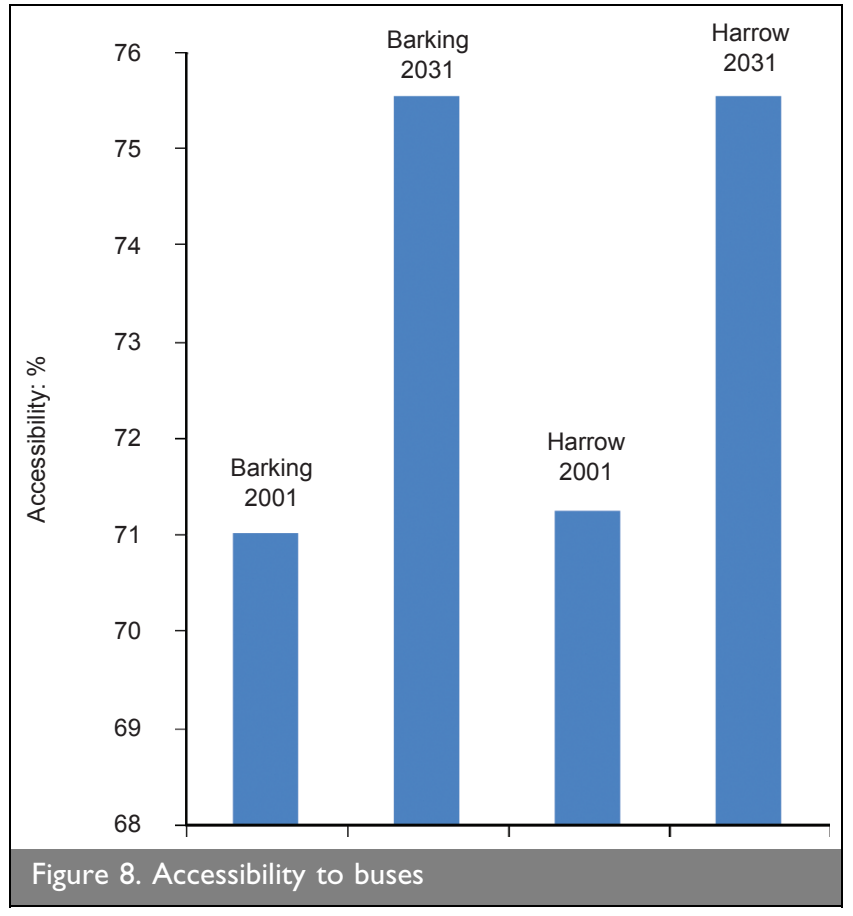

these locations is already relatively good, with levels over 70\%. Retrofitting resulted in an improvement of 5\% by 2031.

Rail, underground and Docklands light railway stations have slightly different pedsheds; for brevity, the data were aggregated with a $400 \mathrm{~m}$ pedshed for segregated rail services (Figure 9). Both case study locations in 2001 had a poor level of accessibility to rail destinations at just over 30\%. Although there was a large increase in accessibility to over $40 \%$ by 2031 , accessibility levels would still be relatively low with 57\% of the population having poor accessibility.

\subsection{Creating the neighbourhood unit}

Figure 2 gives an indication of the physical size and structure of a compact city, or neighbourhood, in principle. Figure 10 illustrates an example of the process of intensification within an existing suburban neighbourhood. The 2001 condition is represented in pale grey and retrofitted dwellings in darker grey. The image shows the intensification of new dwellings nearest

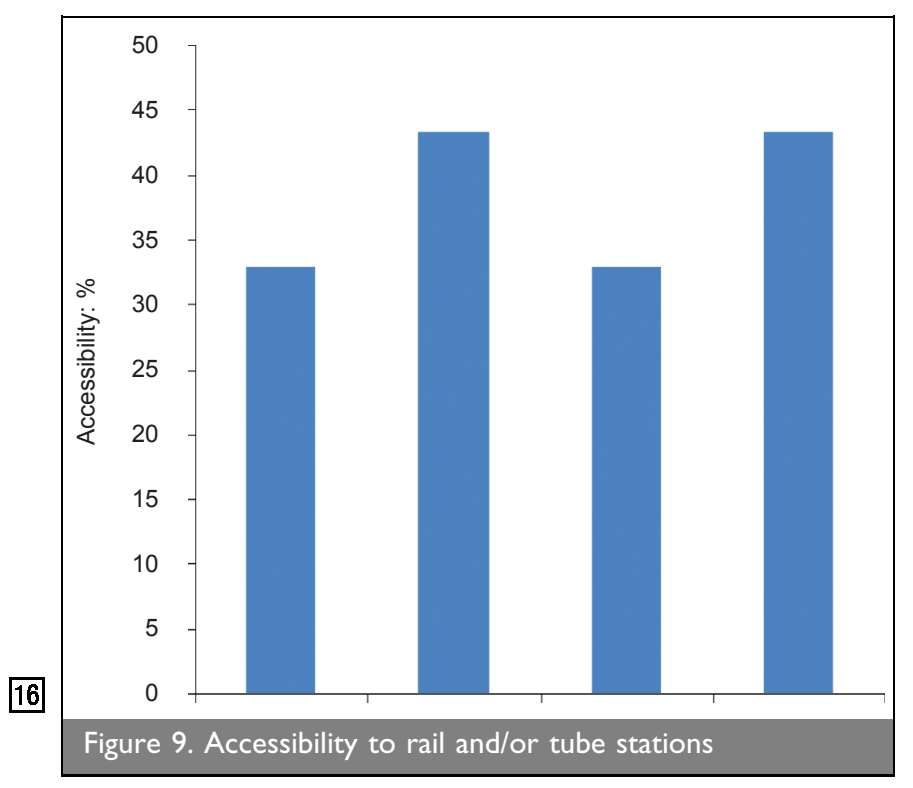

the centre, reducing towards the edges of the neighbourhood. This research examined in detail the creation of 15 neighbourhood units across the study areas. Each neighbourhood was tested to ensure that sustainable density levels could be achieved in accordance with PTALs. It was found that it possible to retrofit all of these neighbourhoods to achieve the required densities. Accessibility levels for schools, services and public transport were also checked for each neighbourhood. The results showed improved levels of accessibility. Lastly, the physical size of the neighbourhood was measured to ensure the $800 \mathrm{~m}$ pedshed was maintained; it was feasible to retrofit each neighbourhood within the $800 \mathrm{~m}$ limit. There was no requirement for large-scale demolition to achieve these neighbourhood criteria.

\subsection{Creating the district structure}

The idealised crystalline form of the district unit has five neighbourhood units surrounding a central neighbourhood (see Figure 11(a)). In this illustration, the optimal 'district' centre relates to the existing 'district' centre in Barking. The compact city strategy would potentially require considerable intensification. There should be approximately 11 neighbourhood areas for a site of this size. Figure 11(b) shows the same site with undevelopable areas removed; these include rivers, floodplains, areas of protected biodiversity and infrastructure such as power stations, motorways and large arterial roads, sewage works and major rail lines. This creates a patchwork of available land. Due to these unavailable areas, there was space for only ten neighbourhood units.

The existing neighbourhoods (see Figure 12(a)) do not have the required density levels, accessibility levels or inter-connectedness required for a compact city. Figure 12(b) illustrates the proposed retrofitting strategy. The existing neighbourhoods were intensified in accordance with UTF criteria for density, accessibility and size. There are also three new neighbourhoods created in areas that lacked existing centres. Despite the feasibility of creating local neighbourhoods, generation of the larger district was compromised. The district unit could only partially be accommodated within this area. The smaller neighbourhoods could not form a cluster around the main district centre. This was partly due to existing infrastructure and topography. The areas that could not be developed or restructured compromised the feasibility of implementing the compact city at this scale. The second case study area found similar results. Despite the creation and re-enforcement of individual neighbourhoods, the district structure was difficult to achieve.

\subsection{Reflections on the research process}

Before coming to the main conclusions of this work, it is worth putting these findings into the wider sustainability discourse. During the period of this research, the context of sustainability has changed considerably. The research carried out attempted to work within a relatively realistic framework. However, the effects and costs of climate change (Stern, 2007) have become far more severe and pressing than at the start of the project, and there are now calls for exploration of more radical approaches and solutions than those presented here. The future of UK suburbs might need to be very different to respond to climate change. These research methods could be used to develop experimental designs and innovative urban forms and to 


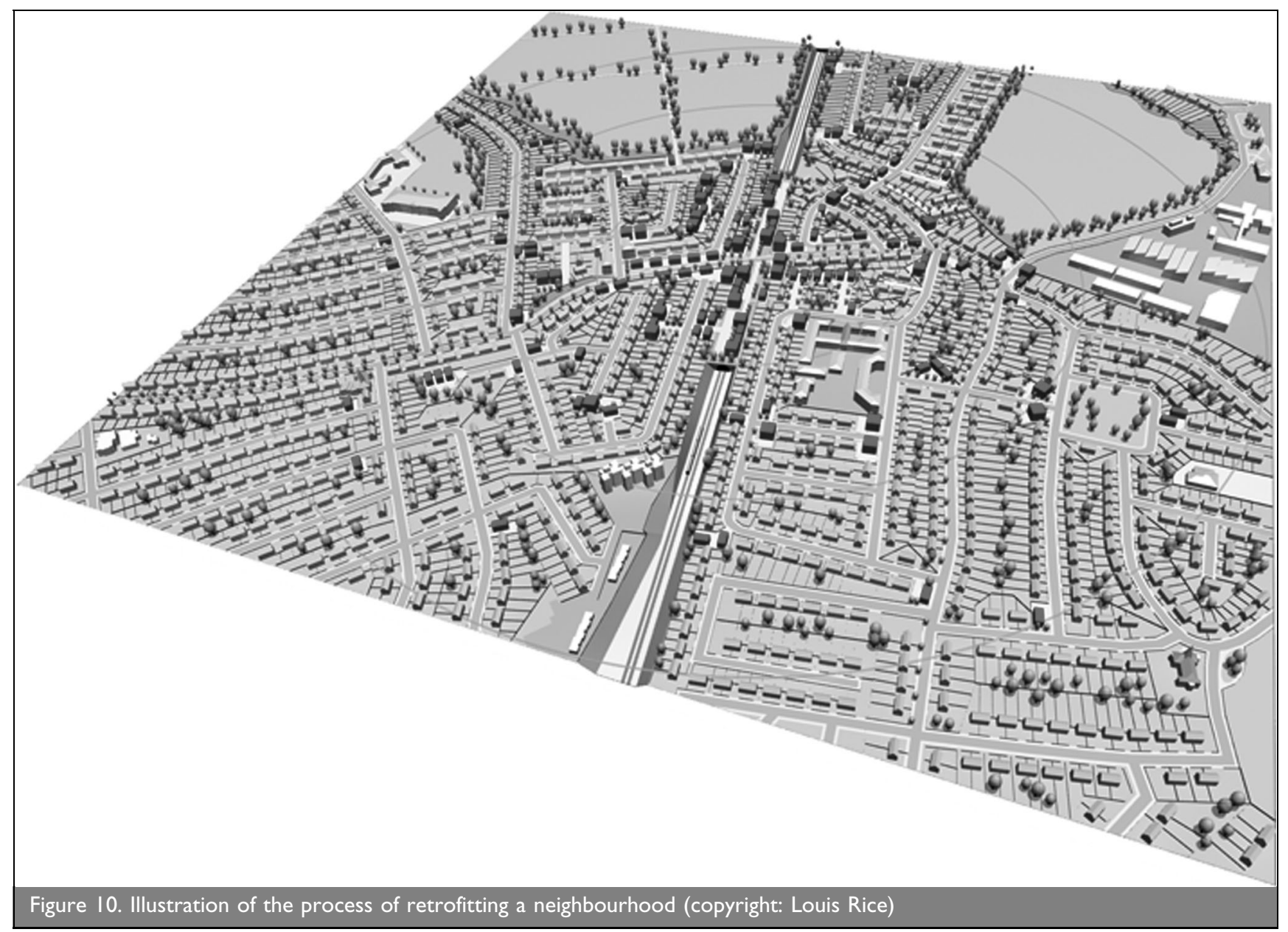

evaluate their implications on sustainability. Furthermore, this paper does not cover the many attitudinal and social issues related to intensifying suburbia although this is a very important issue that should form the focus of further research.

\section{CONCLUSIONS}

\section{I. Is it physically feasible to retrofit existing suburban areas?}

The results were mixed, but overall were positive towards feasibility. Results on density reveal it is physically feasible to retrofit the existing suburbs studied to the 'sustainable' levels proposed by the UTF. Increases in density could be located to coincide with local shops, services and areas with a good public transport network. This intensification should augment and improve those transport services. It was also feasible to retrofit the suburbs to suitable density levels of $50 \mathrm{dph}$ and above. This 'soft-intensification' approach enabled more provision of singlefamily housing rather than the current UK trend of higher density apartment living.

Results on accessibility reveal improved performance through retrofitting. Across all key destinations there was an overall improvement in accessibility. The levels of accessibility attained through retrofitting did increase, although they did not reach the levels proposed by the UTF. Most of the case study areas would see these improvements, but it was not possible in all locations. In practice, accessibility in more remote locations would not improve. These results should also be considered in comparison with current UK accessibility trends, which show a deterioration in accessibility compared with 2001. Retrofitting might not achieve optimal levels of accessibility but it does provide an improvement on current trends and on 2001 levels.

Neighbourhood units were possible through retrofitting, both through re-enforcing existing neighbourhoods and creating new ones. At the neighbourhood scale, retrofitting could be implemented without major physical difficulties. The district unit was much more difficult to achieve. In practice, the complete district could not be produced with a 20 min walk to the centre; at best a 'sub-optimal' district was attained. This resulted in improvements to density but still below sustainable levels. Accessibility was also improved but remained below the level required by the UTF. The sub-optimal district would be an improvement on current tends and on 2001 performance.

\subsection{Does retrofitting deliver sustainability benefits?}

It is much harder to give a clear answer to this question as the delivery of sustainable development benefits requires the assessment of many social, economic and environmental factors. The conclusions are thus to be found in the wider literature on the sustainability benefits to be derived from the compact city. This paper focused on sustainability issues as defined by the physical structure of the UTF compact city. This involved measuring the density, accessibility and physical structure of retrofitted suburbs. Not all locations benefited and hence sustainability benefits would not be equal across the entire study areas. Where it was feasible to retrofit suburbs, there would be likely improvements to some sustainability indicators. The walkable mixed-use neighbourhoods would be more capable of supporting a sustainable 


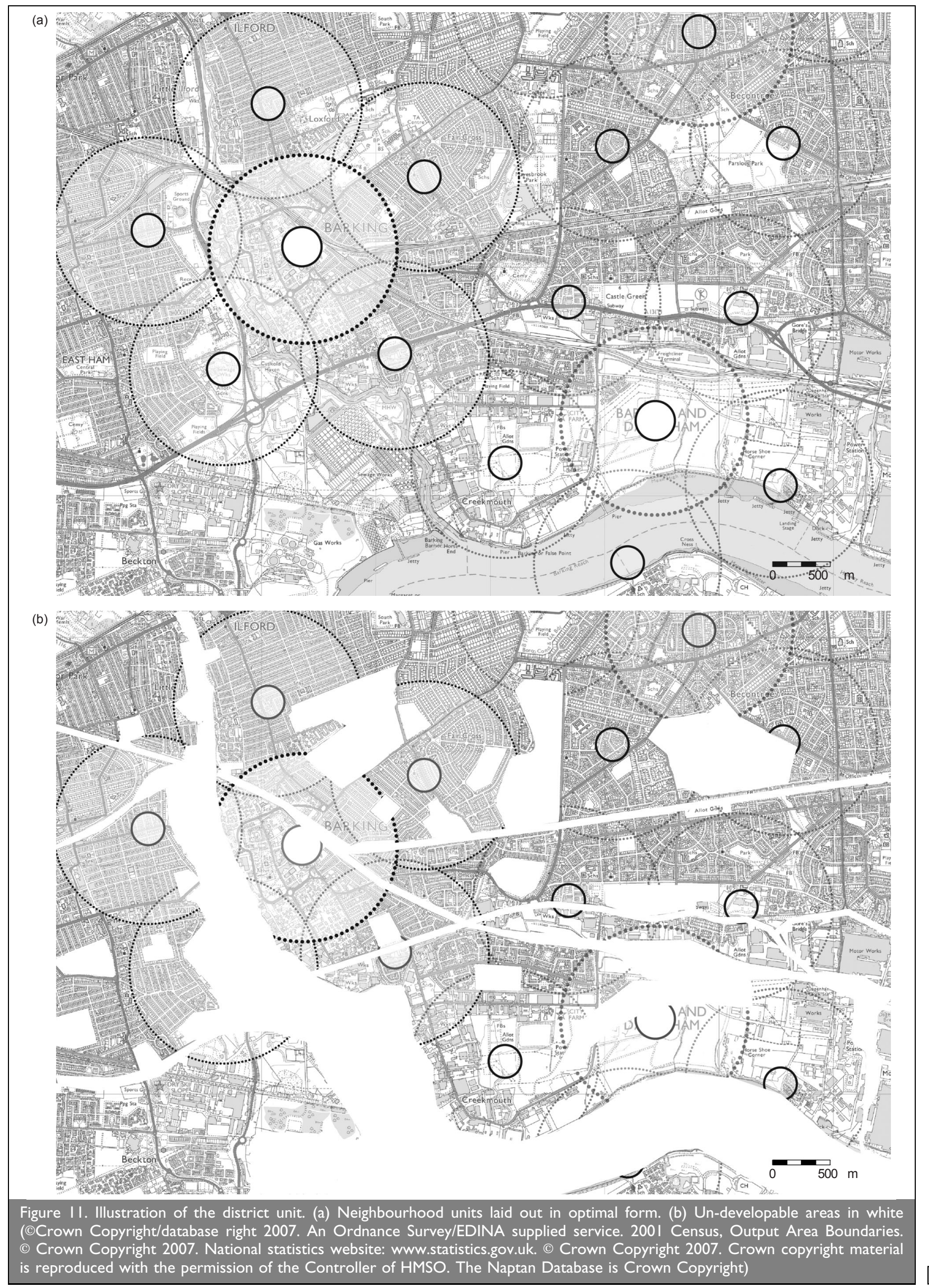

17 


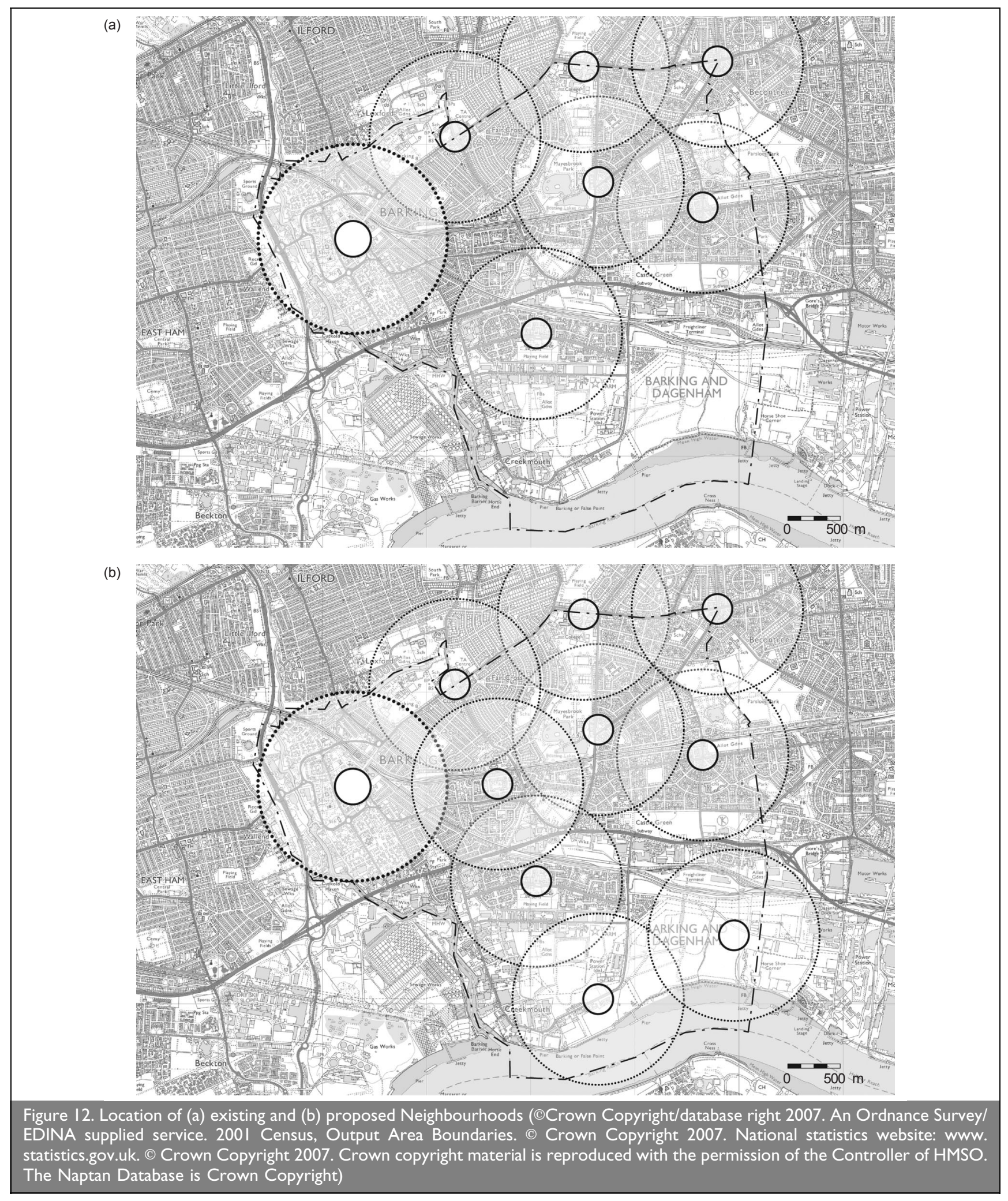

public transport system, with higher levels of walking and cycling. The viability and vitality of local centres would also increase. These would provide increased potential for social capital and community networks, and the highly accessible neighbourhoods could also deliver a range of mental and physical health benefits.

In conclusion, this research has shown that it is physically feasible to intensify suburbia and that there are many potential sustainability benefits in doing so.

\section{REFERENCES}

Barton H and Grant M (2008) Testing time for sustainability and health: striving for inclusive rationality in project appraisal. The Journal of the Royal Society for the Promotion of Health 128(3): 130-139.

Barton H, Grant M and Guise R (1995) Sustainable Settlements: A Guide for Planners, Designers and Developers. Faculty of the Built Environment and Local Government Management Board, Bristol.

Barton H, Grant, M and Guise R (2003) Shaping Neighbourhoods: 
For Local Health and Global Sustainability, 2nd edn. Routledge, London.

Breheny MJ (1992) The contradictions of the compact city. In Sustainable Development and Urban Form (Breheny MJ (ed.)). Pion, London, pp. 138-159.

Breheny M (1995) The compact city and transport energy consumption. Transactions of the Institute of British Geographers 20(1): 81-101.

Breheny MJ and Rockwood R (1993) Planning the sustainable city region. In Planning for a Sustainable Environment: A Report by the Town and Country Planning Association (Blowers A (ed.)). Earthscan, London, pp. 150-189.

Brundtland G (ed.) (1987) Our Common Future: The World Commission on Environment and Development. Oxford: Oxford University Press.

CABE (Commission for Architecture and the Built Environment) (2008) Physical Activity and the Built Environment. CABE, London.

CEC (Commission of the European Communities) (1990) EUR 12902 EN: Green paper on the urban environment. CEC, Brussels.

Dair CM and Williams K (2006) Sustainable land reuse: the influence of different stakeholders in achieving sustainable brownfield developments in England. Environment and Planning A 38(7): 1345-1366.

d'Avoine P and Melhuish C (2007) ONE: MORE. Architectural Research Quarterly 11(2): 118-131.

DCLG (Department of Communities and Local Government) (2006) Planning Policy Statement: Planning and Climate Change. Supplement to Planning Policy Statement 1. DCLG, London.

Defra (Department for Environment, Food and Rural Affairs) (2009) Sustainability Indicators in your Pocket. Defra, London.

DETR (Department for Environment, Transport and the Regions) (1999) Quality of Life Counts: Indicators for a Strategy for Sustainable Development for the United Kingdom: A Baseline Assessment. DETR, London.

DETR (2000) Our Towns and Cities: The Future Delivering an Urban Renaissance. DETR, London.

DETR/CABE (2000) By Design: Urban Design in the Planning System. Thomas Telford, London.

DfT (Department for Transport) (2007) Manual for Streets. Thomas Telford, London.

Dittmar H and Ohland G (2003) The New Transit Town: Best Practices in Transit-oriented Development. Island Press, Washington, DC.

Dunham-Jones E and Williamson J (2009) Retrofitting Suburbia: Urban Design Solutions for Redesigning Suburbs. Wiley, Hoboken, NJ.

Echenique M and Homewood R (2003) The Future of Suburbs and Exurbs. Independent Transport Commission, Cambridge.

Echenique M, Hargreaves A, Jin Y, Mitchell G and Namdeo A (2009) London and the Wider South East Regions Case Study. See www.suburbansolutions.ac.uk for further details (accessed 17/08/2009).

Ecotec (1993) Reducing Transport Emissions through Planning. HMSO, London.

EEA (European Environment Agency) (2006) Urban Sprawl in Europe: The Ignored Challenge. EEA, Copenhagen.

English Partnerships (2000) Urban design compendium. London: English Partnerships.
Falk N (2006) Towards sustainable suburbs. Built Environment 32(3): 225-234.

Frayling C (1993) Research in art and design. Royal College of Art Research 1(1): 1-5.

Frey H (1999) Designing the City: Towards a More Sustainable Urban Form. Taylor \&t Francis, London.

GLA (Greater London Authority) (2004) The London Plan. GLA, London.

Gwilliam M, Bourne C, Swain C and Prat A (1999) Sustainable Renewal of Suburban. Civic Trust for the Joseph Rowntree Foundation, London.

Haughton G and Hunter C (1994) Sustainable Cities. Jessica Kingsley, London.

Jenks M, Burton E and Williams K (eds) (1996) The Compact City: A Sustainable Urban Form?Spon, London.

Kawachi I, Colditz GA, Ascherio A, et al. (1996) A prospective study of social networks in relation to total mortality and cardiovascular disease in men in the USA. British Medical Journal 50(3): 245-251.

Kochan B (2007) Achieving a Suburban Renaissance - The Policy Challenges. Joseph Rowntree Foundation, London.

Larkin M (2003) Can cities be designed to fight obesity? The Lancet 362(9389): 1046-1047.

Lavin T, Higgins C, Metcalfe 0 and Jordan A (2006) Health Impacts of the Built Environment: A Review. Institute of Public Health in Ireland, Dublin.

Lenthe V, Brug FJ and Mackenbach JP (2005) Neighbourhood inequalities in physical inactivity: the role of neighbourhood attractiveness, proximity to local facilities and safety in the Netherlands. Social Science \&t Medicine 60(4): 763775.

Leyden KM (2003) Social capital and the built environment: the importance of walkable neighborhoods. American Journal of Public Health 93(9): 1546-1551.

MJP (MacCormac Jamieson Prichard) (2005) Redefining Suburbia. See www.bdonline.co.uk/Journals/Builder_Group/ Building_Design/06_July_2007/attachments/rr_sustainable\%20suburbia_061023_em.pdf for further details (accessed 08/01/2009).

ODPM (Office of the Deputy Prime Minister) (2003) Sustainable Communities: Building for the Future. ODPM, London.

ONS (Office for National Statistics) (2001) People and their Homes in England and Wales. See http://www.statistics.gov. uk/census2001/profiles/commentaries/housing.asp for further details (accessed 01/12/2008).

Prince's Foundation (2000) Sustainable Urban Extensions: Planned Through Design. Prince's Foundation, London.

RCEP (Royal Commission on Environmental Pollution) (2007) The Urban Environment: Twenty-Sixth Report Presented to Parliament by command of Her Majesty. TSO, Norwich.

Rendell J (2004) Architectural research and Disciplinarity. Architectural Research Quarterly 8(2): 141-147.

Scheer BC and Petkov M (1998) Edge city morphology: a comparison of commercial centers. Journal of the American Planning Association 64(3): 298-310.

Sherlock H (1991) Cities are Good for Us. Palladin, London.

Stern NH (2007) The Economics of Climate Change: The Stern Review. Cambridge University Press, Cambridge.

Stretton H (1996) Density, efficient and equality in Australian cities. In The Compact City: A Sustainable Urban Form? (Jenks M et al. (eds)). Spon, London. 
TCPA (Town and Country Planning Association) (2007) Best Practice in Urban Extensions and New Settlements. TCPA, London.

Urbed (1999a) Building the 21 st Century Home: The Sustainable Urban Neighbourhood. Architectural Press, Oxford.

Urbed (1999b) Tapping the Potential. Best Practice in Assessing Urban Housing Capacity. Department of Communities and Local Government, London.

Urbed/GLA (2002) A City of Villages: Promoting a Sustainable Future for London's Suburbs. Urbed/GLA, London.

UTF (Urban Task Force) (1999) Towards an Urban Renaissance: Final Report of the Urban Task Force. DETR, London.

UTF (2006) Towards a Strong Urban Renaissance. UTF, London.
Wandsworth Council (2004) Wandsworth Hidden Homes. See www.wandsworth.gov.uk/housing for further details (accessed 10/06/2009).

Wilkinson R and Marmot M (2003) Social Determinants of Health, 2nd edn. Oxford University Press, Oxford.

Williams K (1999) Urban intensification policies in England: problems and contradictions. Land Use Policy 16(3): 167178.

Williams K (2009) Space per person in the UK: a review of densities, trends, experiences and optimum levels. Land Use Policy 26(1): 83-92.

Williams K, Burton E and Jenks M (eds) (2000) Achieving Sustainable Urban Form. Spon, London.

\section{What do you think?}

To discuss this paper, please email up to 500 words to the editor at journals@ice.org.uk. Your contribution will be forwarded to the author(s) for a reply and, if considered appropriate by the editorial panel, will be published as discussion in a future issue of the journal.

Proceedings journals rely entirely on contributions sent in by civil engineering professionals, academics and students. Papers should be 2000-5000 words long (briefing papers should be 1000-2000 words long), with adequate illustrations and references. You can submit your paper online via www.icevirtuallibrary.com/content/journals, where you will also find detailed author guidelines. 